East African Medical Journal Vol. 80 No. 1 January 2003

COMPARISON OF VACCINATION STATUS OF CHILDREN BORN IN HEALTH UNITS AND THOSE BORN AT HOME

A. Odiit, Paediatrician and B. Amuge, Senior Nursing Officer and Health Visitor, Jinja Hospital,Uganda

Request for reprints to: Dr. A. Odiit, Department of Paediatrics and Child Health, Mulago Hospital, P.O. Box 7072, Kampala, Uganda

\title{
COMPARISON OF VACCINATION STATUS OF CHILDREN BORN IN HEALTH UNITS AND THOSE BORN AT HOME
}

\author{
A. ODIIT and B. AMUGE
}

\begin{abstract}
Background: The Expanded Programme of Immunisation schedule starts at birth, yet a significant number of child births in Uganda occur at home, where there are no vaccines. A child born at home may therefore have less chances of being vaccinated than a child born in a health unit.

Objectives: To investigate vaccination status of the under-fives and to establish whether vaccination status of children born in health units is better than those born at home.

Design: Cross-sectional descriptive.

Setting: Paediatrics out-patient clinic of Jinja Hospital, a regional referral health facility in Eastern Uganda. Methods: Children under five years were enrolled consecutively as they arrived at the registration desk. The child health card and physical examination for BCG scar were used to establish the vaccination status of each child. A structured questionnaire was used for collecting relevant data.

Results: Of the 486 children sampled, 79 had been born at home, and 407 had been born in health units. Overall, $68 \%$ of the children were fully vaccinated for age. A child born in a health unit was significantly more likely to have a BCG scar $(p=0.0087)$, and to be upto date with their vaccination $(p=0.0173)$, compared to a child born at home. Vaccine drop-out rate was similarly high irrespective of whether the children were born at home or in health units.

Conclusion: Being born at home was found to be a risk factor for incomplete or non-vaccination. Continuation of vaccination was similarly poor in children born at home and those born in health units.
\end{abstract}

\section{INTRODUCTION}

Immunisation to child health and survival in the tropics is very important that it deserves to be frequently reviewed in respective health units, countries, sub-regions and regions. Besides, immunisation is part of a child survival package which includes growth monitoring, oral rehydration therapy, breastfeeding, food supplementation and family spacing(1).

More than three quarters of child births in the developing countries are said to occur under Traditional Birth Attendants (TBAs)(2). On the other hand, it has been found that TBA's may not ordinarily support vaccination of the babies they deliver(3).

The health care providers' knowledge and practice (the health care provider could include whoever delivers a mother at home) of immunisation has been found to be a factor that can affect immunisation coverage(4-5). Gedlu and Tesemma(6) working in Gondar, Ethiopia found that the mother's lack of knowledge was responsible for up to $40 \%$ of children not having been immunised. The health care provider should be the first source of correct and adequate vaccination information to mothers.

Indeed, educating the parents (both mothers and fathers) about immunisation appears to increase the immunisation coverage among the children of both illiterate and literate parents(6-9). Castro-Conde et al. have asserted that the promptness with which children are immunised reflects the quality of care available to the children(10). Therefore, child vaccination coverage might give a verdict as to how good our child health services are. In Mukono district in Uganda, the district health team, using the World Health Organisation (WHO), 30 cluster sampling technique, found DPT crude coverage (a measure of access to health service), to be $65 \%$ among the children less than two years (UNEPI Coverage Survey 1994). In the same study, there was a drop out rate as high as $32 \%$ between $\mathrm{DPT}_{2}$ and $\mathrm{DPT}_{3}$. A similar study in Jinja district (UNEPI 1994) had found a DPT crude coverage of $93 \%$ and also a high drop out rate of $38 \%$ between $\mathrm{DPT}_{1}$ and $\mathrm{DPT}_{3}$.

In Jinja Hospital the paediatrics outpatients' clinic carries out vaccination of children especially the underfives. Well children are brought to the clinic to continue their immunisation after birth while the sick ones needing vaccination are identified by the nurses either among the outpatients or inpatients. The children coming for vaccination could have been born either in Jinja Hospital, other health units or at home.

It is not clear whether the place of delivery of a child influences the vaccination coverage.

Objectives: The main objective of this study was to investigate the vaccination status of children under five 
years of age, attending the Jinja Hospital paediatrics outpatient clinic. In addition, we sought to establish whether the vaccination status of children born in health units was better than that of children born at home.

Methodology: The study was carried out in the paediatric outpatient clinic of Jinja Hospital, situated near the source of the Nile, about $90 \mathrm{~km}$ east of Uganda's capital city, Kampala.

A structured questionnaire was developed for recording each child's demographic and vaccination data. Six health workers (nurses) collected the information using questionnaires. Before the actual process of data collection the questionnaire was pre-tested and a few ambiguities therein corrected.

The sample size was estimated using the formula $\mathrm{N}$ $=\mathrm{Z}^{2} \mathrm{P} \mathrm{q} / \mathrm{d}^{2}$

Respondents were selected using systematic sampling, taking every third mother as they arrived at the outpatient reception table.

\section{Inclusion criteria}

Children below five years of age and in the company of their mothers/other caretakers.

\section{Exclusion criteria}

Children five years of age and above and children not in the company of their mothers/other caretakers.

The investigator explained to the child's mother what the information was for and proceeded with the interview only after the mother's oral consent. At the end of the interview, the investigator re-enforced the mother's knowledge about immunisation, answered any health related questions the mother would have, reminded her when the next vaccination visit should be, and thanked her for bringing the child for vaccination.

A scar was accepted to be due to BCG if it were located at the outer aspect of the right upper arm, approximately at the insertion of the deltoid muscle.

At the end of each day the principal investigator with the other investigators sat down to edit all the questionnaires to ensure that all the required information was correctly recorded.

Vaccination coverage was determined using documented vaccinations according to information in the child health card and presence of a BCG scar.

Criterion for fully vaccinated: All vaccines and doses should have been received at correct ages and intervals according to the Uganda National Expanded Programme of Immunisation (UNEPI) schedule. It was not necessary to have got $\mathrm{OPV}_{0}$ to be considered fully vaccinated.

$\begin{array}{rlll}\text { UNEPI Schedule: } & \text { At } & \text { birth } & \mathrm{OPV}_{0}, \mathrm{BCG} \\ \text { At } & 6 \text { weeks } & \mathrm{OPV}_{1}, \mathrm{DPT}_{1} \\ \text { At } & 10 \text { weeks } & \mathrm{OPV}_{2}, \mathrm{DPT}_{2} \\ \text { At } & 14 \text { weeks } & \mathrm{OPV}_{3}, \mathrm{DPT}_{3} \\ \text { At } & 9 \text { months } & \text { Measles }\end{array}$

Vaccines received outside UNEPI schedule such as during National Immunisation Days against polio or measles were excluded.

Study limitation: Being a hospital-based study, the results might only have provided a hint and may not have been a representative of what was happening in the community.

\section{RESULTS}

Four hundred and eighty six children were studied.

Child card: Only 94(19\%) children had a child health card brought along during the clinic visit. Of the 94 children, 64(68\%) of them were fully vaccinated for age while $30(32 \%)$ were either partially vaccinated or not at all.

Table 1

Vaccines received at correct intervals and age (according to UNEPI)

\begin{tabular}{lcc}
\hline Immunization & Frequency & $(\%)$ \\
\hline BCG $_{\text {and }} \mathrm{OPV}_{0}$ & 94 & 100 \\
$\mathrm{OPV}_{1}$ and $\mathrm{DPT}_{1}$ & 81 & 86.2 \\
$\mathrm{OPV}_{2}$ and $\mathrm{DPT}_{2}$ & 28 & 29.8 \\
$\mathrm{OPV}_{3}$ and DPT 3 & 11 & 11.7 \\
Measles & 5 & 5.3 \\
\hline
\end{tabular}

There was a gentle drop of the percentage of those children who were up to date for their vaccination between $\mathrm{OPV}_{0}$ and $\mathrm{OPV}_{1}$ (i.e. about $14 \%$ ) but a dramatic fall of $56 \%$ occurred between $\mathrm{DPT}_{1}$ and $\mathrm{DPT}_{2}$. Only $5.3 \%$ of the children due for measles vaccines had it at the correct age.

Figure 1

Birth rank and vaccination status

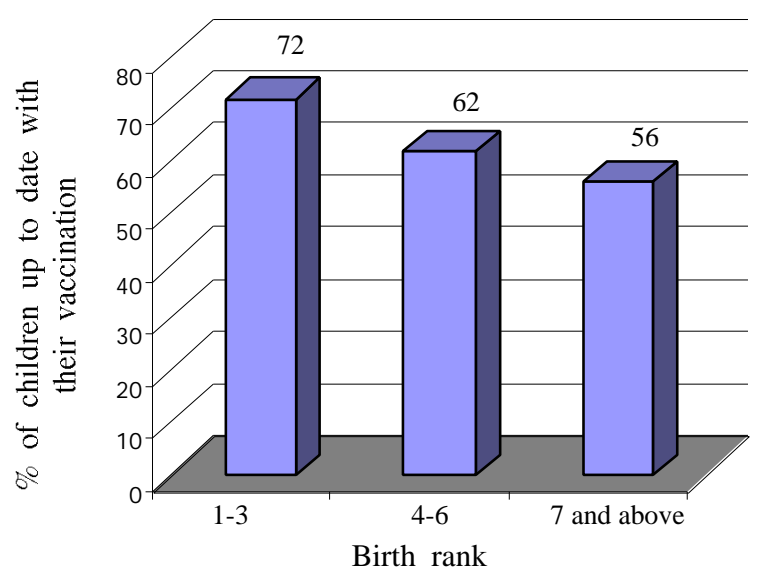

Birth rank and vaccination status: The highest percentage of children up to date with their vaccination (i.e. 72\%) occurred among the birth ranks 1-3. The percentage continued to fall with advancing birth rank. 
Parental basic education and children's vaccination: The children of parents with higher formal education were more likely to be up to date for vaccination compared with children of parents with either low or no education.

BCG Scar: Three hundred and sixty seven $(75 \%)$ of all the children had a BCG scar.

Table 2

Place of birth and BCG scar

\begin{tabular}{lccc}
\hline \multirow{2}{*}{ Place of birth } & \multicolumn{3}{c}{ BCG scar } \\
\\
\hline Health Unit & 319 & 88 & 407 \\
Home & 48 & 31 & 79 \\
\hline Total & 367 & 119 & 486 \\
\hline
\end{tabular}

A child born at a health unit was significantly more likely to have had BCG scar than a child born at home $(\mathrm{P}=0.0087)$.

Table 3

Vaccination status versus place of birth

\begin{tabular}{lccc}
\hline \multicolumn{4}{c}{ Vaccination Status } \\
\hline Place of Birth & $\begin{array}{c}\text { Fully } \\
\text { vaccinated } \\
\text { for age }\end{array}$ & $\begin{array}{c}\text { Partially } \\
\text { vaccinated } \\
\text { for age }\end{array}$ & Total \\
\hline Health Unit & 56 & 20 & 76 \\
Home & 8 & 10 & 18 \\
\hline Total & 64 & 30 & 94 \\
\hline
\end{tabular}

Vaccination Status Versus Place of Birth

Significantly more children born at health units were fully vaccinated compared to the children born at home. $(\mathrm{P}=0.0173)$ (Mantel-Haenszel)

\section{DISCUSSION}

The low child health card carriage to the clinic of $19 \%$, generally makes determination of vaccination status of children difficult in Jinja Hospital. An absent child health card may lead to a missed immunisation opportunity when a health worker insists on a child health card before vaccination. Without the child health card, the vital health information contained in the child health card becomes unavailable to the health worker for use in management of the child's health.

Sixty eight percent of the children were up to date with their vaccines. This compares favourably with the national average of $47 \%(11)$. Assuming that parents who brought their children to hospital and thus participated in this study represented the section of parents with good health seeking behaviour, a community-based study would probably find a figure lower than $68 \%$ as being up to date with their vaccination.

The fact that $75 \%$ of children had a BCG scar and that $86 \%$ of them had $\mathrm{DPT}_{1}$ testifies to good access and use of vaccines in the catchment area of our outpatient clinic and compares well with $93 \% \mathrm{DPT}_{1}$ coverage found in the 1994 community surveys by UNEPI in Jinja district. There is a precipitate fall between $\mathrm{DPT}_{1}$ and measles. The delayed vaccination against measles explains the presence of measles cases in the paediatrics unit of Jinja hospital throughout the year for the last four years (Jinja Hospital records 1995-1999). It is also evident that good access to vaccines needs to be followed by good health seeking behaviour of parents to bring their children back to health units or to immunisation outreach posts for continued vaccination.

An increasing birth rank appears to be matched by a declining percentage of children who are up to date with vaccination. This may be a reflection of reducing family resources available to an individual child the more children a family has. On the other hand, family spacing may re-inforce child vaccination in that the parents would have the time, energy and resources to take the child for vaccination.

Our finding that children born at home were less likely to be vaccinated than children born at a health unit points to the need for community focused approaches to vaccination. Communities, through community health care workers, TBAs and parish development committees should be made to participate in routine child vaccinations. The training of TBA's should include an emphasis on referring the child for vaccination after birth. These measures would ensure that children born at home, either under a traditional birth attendant or other, should not significantly be missing out on vaccination.

There are other challenges to overcome in order to increase the proportion of children who are upto date with their vaccine. The challenges include; lack of knowledge among parents and health workers concerning different issues of child immunisation(3) and poverty at both family and national levels which does not allow child vaccination to be the priority it should be.

In conclusion most children $(>75 \%)$ coming to Jinja paediatric outpatients clinic will have had their first vaccines but continuation of the vaccination schedule is rather poor. A child born at a health unit is more likely to be fully vaccinated than a child born at home.

\section{ACKNOWLEDGEMENTS}

To the Hospital Administrator and Medical Superintendent Jinja hospital for their encouragement and material support. Dr. Sarah Byakika for data handling. 
Prof. J. K. Tumwine for his valuable suggestions. All parents and child caretakers who brought their children to the clinic in time for vaccination.

\section{REFERENCES}

1. Bennett, F.J. Essential elements of child survival and development. In: Diseases of children in the tropics and subtropics. Stanfield, P., Brueton, M., Chan, M. et al. (eds) 4th ed. ELBS, Arnold, London 1991 Chapter 3 Pg 31.

2. Owen, M. Traditional birth attendants and the law. World Health Forum . 1983; 4: 291-312.

3. Tugumusirize, F. Vaccination coverage, missed vaccination opportunities and caretaker constraints to childhood vaccination in Kiyeyi, Tororo district. M.Med dissertation (MUK) 1999.

4. Wood, D., Halfon, N. Pereyra et al. Knowledge of the childhood immunisation schedule and of contraindications to vaccinate by private and public providers in Los Angeles. Paediat. Infec. Dis. J. 1996; 15: 104-105.

5. Williams, I.T., Milton, J.D., Farell, J.D. et al. Interaction of Socioeconomic status and provider practices as predictors of immunisation coverage in Virginia Children. Paediatrics. 1995; 96:439-446.

6. Gedlu, E. and Tesemma, T. Immunisation coverage and identification problems associated with vaccination delivery in Gondar, North West Ethiopia. East Afr. Med. J. 1997; 74: 239-241.

7. Dhadwal, D., Sood R. Gupta, A.K. et al. Immunisation coverage among urban and rural children in the Shimla hills. J. Сотти. Dis. 1997; 29:127-130.

8. Brugha, R.F., Kevany, J.P. and Swan, A.V. An investigation of the role of fathers in immunisation uptake. Inter. J. Epidem. 1996; 25:840-845.

9. Rahman, M., Islam, M.A. and Mahalanabis, D. Mothers' knowledge about vaccine preventable diseases and immunisation coverage in a population with high rate of illiteracy. J. Tropical Paediat. 1995; 41:376-378.

10. Castro-Conde, J.R., Mendez, A.M. et al. Is there a relationship between vaccination coverage and paediatric health care? An-ESP-Paediatric. 1997; 46:114-118.

11. Uganda Demographic Health Survery (UDHS) 1995. Ministry of Finance and Economic Planning, Statistics Department, Entebbe, 1996. 